\title{
Examining of the Factors, Effects and Mechanisms to Combat Females and Children Business at the City of Bahirdar, Ethiopia
}

\author{
Dagnachew Nega (Lecturer) \\ Debre Tabor University
}

\begin{abstract}
Sex business is one of the fastest growing businesses. Currently no sites can be immune or free from such business. The objectives of the study are to assess the factors, effects and mechanisms of combating females from sex business. Snow ball sampling technique was chosen. The findings showed that poverty, lack job opportunity, peer pressure, modernization and migration were the main motivating factors. Whereas the effects of participating at the sex business were transmitting disease like HIV AIDS, feeling loneness and losing moral values, creating bad images of the destination and the country at large. The mechanisms suggested through the respondents where cooperation of the stakeholders, establish laws, rules, regulations and policies to prevent the practices, creating awareness to the victims' families, to the general public of the destinations. Generally, the stakeholders should be stand together to stop such practices to save females and children.
\end{abstract}

Keywords: sex business, effects, motivating factors, Bahirdar

DOI: $10.7176 /$ RHSS/9-3-05

\section{Introduction of the study}

Starting from the ancient time, travel and sex may have a special connection. Tourists need to entertain in the developing nations with a very low price. Then can get any ways of relaxation mechanisms which also leads them towards sex (Frans de Man and Adama Bah: 2013). Sex tourism is usually defined as movement of people from rich countries to poor countries mainly to engage in sexual practices and services with local females, and children in exchange of money or other materials (Tepanon, 2006; Davidson and Taylor, 1994, Sontvedt, 2009).

Sex business is usually referred to as the oldest trade in the world. Because of the industrialization in the early 1900 's and the resulting globalization, destinations have become available especially for tourists from the rich nations. During the Vietnam War the U.S army helped to establish sex tourism in south East Asia, when thousands of marines went to Thailand and other boarding countries looking for sexual contact with females (O'Grady, 2008; Bunn D. (2011). In the past South East Asian countries namely Thailand, Philippines, Indonesia, South Korea and Sri Lanka have been the major tourist arrival centers for sex tourism business. However, today the practice of sex tourism business spreads and rapidly growing to different areas of the world ((Valeriu, 2013; Omondi, 2003; O'Grady, 2008).

Sex business is a phrase of huge and obscene economic inequalities between the rich and poor countries, and it is also explained between the wealthy peoples and poor peoples in poor countries (Davidson and Taylor, 1995). Sex business is incredibly diverse and hard to draw exact lines between different relationships and activities (Davidson, 1998). The degree of sex business goes away from the exchange of sex for currency. Institutions like airlines, bars, hotels, entertainment facilities and travel agencies employ millions of workers. But even in spite of the size and economic importance of sex business, it is almost entirely unregulated and goes unrecognized in official figures of almost all countries worldwide (Ives, 2001; Bunn D. , 2011).

Poverty is the cause of motivating sex business. An especially poor country where their economy is largely dependent on tourism is easily leaded towards such business (Klain, 1999; kibicho, 2009; Gore, 2009). In the sex business, there are brokers who join sex workers to foreigners and tourists. Local guides, drivers, receptionists or hotel owners and tour operators are also actors in joining tourists and sex workers (Ayode and Tadele, 2010). Most importantly, the Internet has played a key role in facilitating the expansion of sex tourism networks. Some abusers make arrangements to have sexual contact with females and children even before they leave their home countries (ECPAT International, 2008; Gore, 2009; Joseph, n.d). Other contributing factors include government which means that corruption, absence of or inadequate laws, weak law-enforcement measures, and limited sensitization of law- enforcement personnel to the harmful impact of sex tourism business (Draft Declaration and Agenda for Action, 1996; Klain, 1999).

Even though, the tourism sector provides lots of contribution to many poor countries, there are also plentiful negative impacts. For instance, tourism can result unhealthy issues to the communities' members, especially to females and children through sex tourism bushiness (Ferran, 2008; Sisavath, 2011; Cullen, 2010).Because many females and children around the world are being trapped in the sex industry (ECPAT International, 2009; Tepelus, 2008: Phouthone Sisavath2 011). Health related effects like exhaustion, infections, venereal diseases run rampant among these victims, psychological trauma, The majority of female survivors have substance abuse problems as they turn to drugs and alcohol in order to cope with their pain; they feel unloved, ashamed and worthless(Klain, 1999; Joseph, n.d; Cullen, 2010). 
In many of the developing countries, informal sector is inseparable from the sex trade industry of females and children (Quintanilla, 1997). It is based on system that offer services such as tourist guides, prostitutes, brothels, massage parlors, that serve not only foreign sex tourists but also domestic customers (ibid). This type of sex exploitation can occur anywhere in the world and no country or tourism destination is untouchable. Each year, over a million females are exploited in the global commercial sex trade and in relation to this, since sex tourism involves people who travel from their own country to another and engage in commercial sex acts with females. The commercial sexual exploitation of females has devastating consequences for these minors, which may include psychological disturbance, HIV/AIDS, drug addiction, unwanted pregnancy, starvation, social banishment ((Valeriu, 2013; Global Education Centre, 2005).Like other countries, sex tourism business in Ethiopia has long history. It was believed to be started during the 16th century. During that time, sex tourism business was widespread in Ethiopia because of Italian invasion and building of the Ethio-Djibouti railway (Pankhurst, 1974 and Nick, 2006; cited in Overs and etal, 2011 and Tarekegn, 2008).

\section{Statement of the Problem}

Service is a dynamic industry which is facing lots of challenges. Most of the challenges are also focused through vulnerable groups such as children and females and youth. More importantly tourism industry is a simple way to meet them at the accommodation centers like cafes, restaurants, resorts, hotels, bars, and the like (UNWTO, 2014).

Due to social and others factors, lots of females and children are forced to involve in sex business. And it is usually true for the poor countries where there is tourism development (Arshad, 2012). This implies that Sex is expanding rapidly in the world particularly in third world countries including African countries; and Ethiopia is also affected by sex tourism (Biazen, 2010). The issue of sex business is not talked openly in most Ethiopian societies. This is because of their culture and tradition (Andargachew, 1988; Ayode and Tadele, 2010). Sex tourism business is becoming highly increasing and diversified speedily in different parts of Ethiopia especially in tourist destination areas, regional towns and the capital of the country, Addis Ababa; which receives the highest share from all parts of the country (Tarekegn, 2008; Ayode and Tadele, 2010). In relation to this growth of the tourism sector, the number of sex workers in Ethiopia is equivalently increasing. Many hotels, bars, night clubs and restaurants are becoming the home of various prostitutes (Mulualem, 2010). Sex business is a disgraceful attack on the dignity of females (Valeriu, 2013; Quintanilla, 1997; Arshad, 2012).

Some studies showed that sex business is doubling-up itself in a fast rate particularly in developing countries. There is no hemisphere, continent, or region unaffected by the sex trade. Many minors are attracted to entering the area of sex tourism business because they see the wealth of foreign tourists. Tourism is not the cause of the sexual exploitation of minors, but it does provide easy access to vulnerable groups (Quintanilla, 1997). As a result of its hidden nature and difficulty of getting exact information is not defiantly known in Ethiopia (Saewyc EM, et al, 2008; Tarekegn, 2008). Currently, a number of African countries do not have the relevant mechanisms to protect females from commercial sexual exploitation in tourism (Kibicho, 2009; ECPAT International, 2007). Research on client's motivations and characteristics has previously been left out of literature regarding the sex industry (Sanders, 2008). Tourists seeking sexual experiences with children, females and youths are fueling an industry that crosses the globe (Gore, 2009). Moreover, for females and children, the opportunity of meeting tourist customers is increasing from time to time (Ayode and Tadele, 2010). As it is depicted through different authors, sex tourism business is growing fast and doubling itself from time to time at the regional town, top tourist destination sites, capital cities in Ethiopia. Bahir Dar is one of the top most tourist destination sites in Ethiopia. No tourist will go back to his home place without having two or more night at Bahirdar. Thus, researcher stands to examine the motivating factor of involving on such business, its effect and looking for mechanisms to save females and children from such shameful kinds of business at the tourist destination area, Bahirdar.

\section{Objectives of the study}

- To identify the factors those enforces females and children to involve in sex business.

- To indicate the effects of females and children from participating in sex t business at the study area.

- To show the protection mechanisms to combat females and children from involving in sex practices.

\section{Methods and Materials}

Descriptive type of research design was employed to answers the questions of this particular research problem at the study area. More over descriptive research is used to obtain information concerning the current status of the phenomena and to describe "what exists" with respect to variables or conditions in a situation. The study adopted qualitative approach only since it helps to find out the uniqueness of each particular situation by explanation and understanding the situation specific phenomenon through naturalistic, qualitative inquiry.

The target populations in the study ware the Amhara regional tourism and culture experts, the tourist information office, females who are working on sex tourism business, street females and children, police officers at Bahirdar office, Local tourist guides, hotel receptions, taxi drivers. Since information can be found on the hands of few people, a snow ball sampling technique was used to select the informants who participate in this study as 
informants. Under this, researcher used snowball sampling techniques. Totally, 47 respondents were selected and the numbers of respondents was determined based on the level of data saturation. The researcher has conducted a semi structured interview to gather the required primary data. Through this instrument, the researcher asked participants general, open-ended questions and records their answers. It is probably the most basic way to collect data: the researcher records what he or she observes. Marshall (2006) stated that observation entails the systematic noting and recording of events, behaviors and artifacts or objects in the social setting chosen for study. Documents from different journals, manuals, reports, web sites, office files, video and related books have been searched. Thematic analysis has been undertaken for this particular study. Before the actual analysis of the data, the collected data was sorted and categorized in accordance to its source and type. By looking for key terms and phrases, the transcripts of key-informant interviews, were reduced to manageable blocks of text, from which relevant quotes have been selected.

\section{Results and Discussion}

\subsection{Motivating Factors Which Enforces Females and Children to Involve in Sex Tourism Business}

Most of the respondents agreed that there are many factors for involving in the sex tourism types of business. As it was explained through the tourism experts in the zone, the zone is known through its top tourist's destination. There are many tourists who are coming to the city for relaxation. Some of the tourists are looking sex for entrainment. As explained through most informants, the following are the most prominent factors to involve in sex tourism business.

\section{Level of awareness, lack of accurate and up-to-date information}

$\mathrm{Al}$ most no one has an information regarding the issue. Many literatures assured that as the tourism industry is diversified at the tourist attraction area, the local females and children are also become the major for both the domestic and foreign tourists with a hidden agenda for sexual interest. In Ethiopia, talking openly about sexual activities is a social taboo. Very little is known about the magnitude and nature of the problem in the country. However, sex tourism is growing fast from time to time (FSCE, 2008). Most of the local communities and the government bodies in Bahirdar city have no any idea about the sex tourism practice. Most of the populations of the city assume that talking about the issues is considered as a shameful and better to remain silent. Females and children are only looking the financial benefit they may get from sex tourists. They have no idea about its long term effect. However some of the informants agreed that some of the females have full information about the negative impacts of involving in the sex tourism business and they are keeping on with ignoring its drawbacks. Generally in Ethiopia, awareness and Information on the problem of sex tourism is further complicated and most of the cases remain unreported or under reported (ibid).

\section{Poverty}

Most documents agreed that no one remains to be a poor in the world. Every people need to be rich. To survive and to be rich, everyone tries his/her best in most rural areas since peoples are living on hand to mouth situation. Most of the rural peoples are based their livelihood on agriculture. Most respondents agreed that many of the females will motivate to involve on such sex tourism business just since they are poor and need to be rich. As most of the receptions at hotels explained that many poor females are becoming rich after they involve the business. There are many females who have their own cars for the purpose of running the business.

One of the informants who are working from the sex tourism business explained the situation as followed: I came from Zenzelima village. There in my kebele, there is no option to get money easily. My families are very poor. We are living on hand to mouth situation. My last option was travelling to Bahirdar to look for different jobs. Here I met my friend who came from my kebele and is working on sex tourism business. She is looking new comers, tourists. She is very rich. Then I had no option to ignore this opportunities. It doesn't require nay prerequisite; no criteria at all; it needs only an interest to do that. So I felt this business can change me easily. After all, now I have my own car. I am helping my families. No problem. Actually I may be stressed with full of risk since the business is a difficult and condemned practice through the community. No matter how am not poor. I have enough capital. I can eat special food. I can enjoy at every luxuries hotels in my country. I have my own house in Bahirdar.

As depicted from most of the informant's response, poverty takes the prime share to be the prominent factors which motivates most of the females and children to involve in the sex tourism business. Sex tourism is a multibillion dollar global industry where in sex tourists from developed nations travel abroad with the diverse purpose of purchasing a variety of sexually associated services (Hanum, 2002).

\section{Terminating school and losing Job Opportunity}

Most of the informants agreed that lack of Job opportunities is one of the most important factors for developing sex tourism business. After graduating at any academic institutions, no one needs to remain jobless/unemployed. If students are lacking job after competing their schools, they will involve on different irrelevant and bad 
businesses. Most agreed that many females in Bahirdar are looking sex tourism business as one of the option to sustain their life.

One of the respondent found around kebele 5 illustrated the situation as follows:

I graduated my diploma at college with the profession database level 3 in Bahirdar city. While I was learning, I was very interesting and I wishes to get job with my occupation. However I couldn't get job still. My families are waiting support from me since they thought as I would get job as soon as I graduated from college. However I couldn't get as per my wish. Getting the right job with the right educational background is very hard today especially for females. Most of the time jobs are accessed through corruption. I have no relatives here who can help me on employment. I have tried a lot to get job in different private and government vacancies but I couldn't get as per my wishes. I found sex tourism business is a very simple way to survive. There is no bureaucracy, there is full freedom to do and not to do it I found it enjoyable business.

Another street child quoted the following:

I was very interested to learn and to achieve my vision. I need to be Doctor while I was in grade 4. However I couldn't continue after grade 6. My families were interested to make me married as per their choice. I said no since I was an early child and have an interest to reach at higher level through my education. Unfortunately, I was an intelligent student in my class. During that time I preferred to leave my family and to look for another alternative to continue my education. In Bahirdar city, I joined as home worker through one broker. The owners allowed me to learn at the night. My owners were very hard. They had no care for me at all. I tried to attend school for one year only. I have passed many challenges while I was going from school to my home tonight. One upon the time, one of my classmates told me as there is a good business which will make me profitable and easy to do. He contacted me white tourist. He is very rich. He promised me as he will help me for long for finishing my school. I believed him. However at the end after he stayed with me for 3 days in Bahirdar at hotels, he ignored me by giving only little money. The broker also contacts me for another. I joined the sex tourism business on such a way. Now, I hated my life but I have no choice!!!

In Bahirdar city, tourism experts agreed that not only job opportunity, most of the time many females and children have also fewer educational opportunities or the skills for employment and are forced into this means of earning money. Large numbers of children and young people in many countries in the region are forced to leave school or are unable to continue their education to higher levels because they need to look for employment to provide economic support to their families and/or themselves (ECPAT International, 2008).

\section{Peer Pressures}

Sex tourism business is now become wide spread in Bahirdar city through the peer pressure motivating factors. Most informants agreed that many females are influencing through their near friends and relatives. Victims are telling and convincing their near friends to involve in sex tourism business to become rich with short period of time. Here as most informants agreed that the practice is running with a great secret as the business is condemned through the social communities.

The following quote was taken from one of female informants influenced through peer pressure: I came from Bahirdar Zuria woreda. I have two best friends here in the city are working in sex tourism business. While I was coming for the first time to Bahirdar, they were welcoming me with a good approach. Then they tried to tell me how they could be changed easily through participating in the sex tourism business, I have become impressed since they are really changed in economical and even help their family. I know that they were very poor. Even they couldn't eat properly. They have had no clothes. Look, now there eat special food. They can relax and entertain at any luxury hotels in Bahirdar city. Who dislike living on this world on this way? Thanks to them I am doing what they are doing and live like them. Though the business has no safety, currently it is good to be rich easily.

As per the finding of the authors, peer influence and lack of awareness were told as the main factors to the sex tourism problem (Ayode and Tadele, 2010).

\section{Modernization and Migration}

The migration is held from the rural part to the urban area. There are many rural areas around the capital city of Amhara region, Bahirdar. Most of the documents assured that those who are living at the rural area are believed to be uncivilized and backward where as living in the urban is considered as modernized and civilized society. Thus, there is migration from the rural area to the urban area continuously. From here females and children take a great share. They are flowing to the city of Bahirdar from their rural and remote area to join modernization society.

Interview with the more of respondent assured that as migration increases and borders open more worldwide, sex business is becoming a growing concern. Larger populations and poor economic conditions create opportunity 
to exploit people in sex industries, while international travel provides consistent demand and a sense of anonymity to the practices. Most informants agreed that in the modern world, sex tourism generates billions of dollars annually. Kibicho identifies that environment that directly influence the function of tourism generated sex business. Environment includes the global marketplace, government policies, local community and societal trends etc, which directly or indirectly influences the sex tourism practices (Kibicho, 2009). The development of technology has not only facilitated the growth of the tourism industry but has also strengthened networks of sex abusers mainly preferential sex abusers. New technologies are used to promote and facilitate child sex tourism (Valeriu, 2013; ECPAT International, 2008).

\subsection{Effects of Participating In Sex Tourism Business at the Destination Sites Exposed for different Disease}

There are many diseases which can be transmitted from one person to another through participating on sex tourism business. Most informants agreed that females who are participating on such business can easily be exposed for HIV AIDS, trichomoniasis, human papillomavirus, scabies, syphilis, gonorrhea, hepatitis B virus and other transmitted disease from one person to another and other transmitted disease. As most said the nature of the business is not safe for preventing one's life from such disease. Most tourists who are relaxing themselves through participating on such practices are carless since they should pay for it. Even most informants illustrated that some of the tourists wants to pay more for having sex with females without condom.

One of the informants from tourist guide said the following:

Most females who are working in the business are vulnerable to variety of disease. Some tourists are coming to do it freely for getting personal satisfaction; some tourists are paying much money to have sex without condom; some tourists are careless and hopeless with their nature. Due to these reasons, most females are becoming victim. Regarding me, I don't want to give my blood be tested. I have no hope.

\section{Losing Moral Values and Loneliness}

Losing the moral values can be the result while peoples are doing practices which are condemned through the local culture and be out of the social norm and habits. Most of the informants agreed that one of the most critical effects of participating in sex tourism business is feeling loneliness and losing the moral values.

One of the informants' from one of the core areas of sex work which is kebele 5 said the following: I am feeling bad through many dimensions. I am Christian in my religion. I have learnt many do's and don'ts as per the commandments of the holy Bible. After involving in this business. I am looking only new customers who came from other places. No moral and religious values I want to remember today. I am another person. Life is full of ups and downs. I don't care for everything even for myself. I am living freely. No rules, regulations, religion, no friends, no families and other issues I am worried for. I am losing my moral values. Sometimes I thought I am not human being. I have no friends. They are leaving me. Even my families don't want to talk and meet with me. The local peoples refrain themselves from meeting me. I am sleeping all the day and moving tonight for the business. I am praying God and waiting the time to be free from such hard business.

Study assured that most of the female and children who are involving in sex tourism business are living alone in their home or they are living together since they are doing the same practices. They lack confidence to live with other peoples. Even though most females are looking more money through losing their moral value, the price for sex is cheaper (Hanum, 2002).

\section{Creates Bad Image for the Destination}

Different files assured that sex tourism business is considered as one of the negative implications of tourism development at the tourist destination sites. Most agreed that it has direct roles on diverting the good images of the destination towards bad image. The practice is going to be wide and open the means to attract lots of females and children to join the business. Thus, the norms and cultures of the local communities will easily be ignored. Most agreed that Ethiopia is the known with being the home of many religious practices and most religious norms ignore the sex tourism types of business. Such practice is believed to be condemned through all the peoples of the country.

One of the respondents from the local household answered as follows:

It is the practices of Evil sprite! Once involving into the business, it is difficult to leave it. The business can change the culture, the norm, the identity of our females and children. Above all it spoils the good image of the country. Ethiopia is the unique country. Everybody should be take care regarding the issues. It is spreading on silent mood. Go to the street on the main road. You can get lots of children and females who are looking the new comers/tourists, they are doing the sex tourism business and they are creating the bad images for the destination and for the country as a whole. 
One of the Informants from the receptionist illustrated the following:

Even though sex tourism business is not an open business, there are many females and children who are depending on this business. They are doing it secretly as it is the most ill and socially abused types of business. Unless the issues gets appropriate attention, it is going to be spread widely as the tourism development is growing. We all know that Ethiopia is the holy place. It is the home of many religious events. Ancient spiritual destinations, arc of convenient, lots of monasteries, ancient manuscripts and books. It is good to promote what we have for tourists from different corners of the world. From time to time, due to such tourism a resource, tourist flows is growing the tourism development is increasing. Most of the time tourists are coming to explore what we have however some tourist may want to experience and get satisfaction through sexual activities with the local female and children with a low price during their stay. At last, it creates bad image for the destination.

In general involving in the sex tourism business can lead the females and children to get more vulnerable and for their private and social life to be affected. Most documentary analysis revealed that sex tourism can erode the economic, social, and moral integrity (Ayode and Tadele, 2010).

\subsection{Mechanisms to Combat Females and Children from Involving Sex Tourism Business}

Though it is growing fast from time to time, there are many mechanisms which should be implemented through different stakeholders timely and effectively to combat the practices and save our females and children. The following are some of the most basic mechanisms to minimize and eradicate such practices.

\section{Psychological, financial and counseling support}

Children and females who are working in such sex business need psychological, financial and counseling support from different stakeholders. They can be confident and feel equal with other females and children if they can get such support from the local communities and responsible bodies. Losing one of their parents for females and children is very risky for growing and be equal through many accesses like their neighbors friends. So lacking such support will make them leaving school and joining hard business like sex work. Most of the respondents revealed that if they can get psychological, financial and counseling support, they will terminate from doing such risky business and they feel encouraged and motivated to involve in different profitable business.

\section{Creating Awareness}

As revealed from observation and interview most agreed that the sex tourism business is a very difficult issue. Teaching females continuously through organized way is one of the basic tools to eradicate sex tourism business from the tourist destinations sites. The main reason to provide training regarding such issues is to alleviate the negative consequences which can be happened on females and children.

One of the respondents who were police man working at Bahirdar said the following:

There are many females and children who have no any awareness regarding the serous impacts of the sex tourism business. Bahirdar is one of the most famous tourist destination sites in Ethiopia. Lots of domestic and foreign tourists are staying at the destination. There are core areas where such negotiations regarding sex tourism business are dealing. Most of the time, it is happening on the street through active brokers. Another option is through using phone. There are lots of street females and children who are looking for having sex and get money in return. No one is giving care for such business workers. They are our sisters. Tomorrow is depending on today's children. Mostly, only NGO's are standing for this issue. What about their country government? Is there is no NGO's what will be happen for such sensitive issue. Government should focus on sex tourism business at the tourist destination area like Bahirdar city. Trainings should be provided for such vulnerable groups. These can be conducted through tourism stakeholders in organized manner.

It is indispensable to continue increasing the awareness of children, females, families, tourism professionals regarding the negative impacts (Valeriu, 2013).

\section{Establish strict laws and regulation against Sex Tourism Business}

There is no tourist destination country which is free from sex tourism practices. Many authors have been expressing the prevalence of sex tourism business where there is tourism development is growing. Setting and implementing the laws and regulations is one of the mechanisms to minimize the participations of females and children from involving in the sex tourism business. Even though the practice is held on security, there is no standard rules and regulation to combat the sex tourism business in the country. The result of interview among informants revealed that there is no strong law regarding this issue. There are many brokers who are doing on such situation, anybody may watch while females and children are enforced through different reason. However since there is no strict rules and regulation, more parties are involving in the business with secret. It has great drawbacks when it comes to the implementation and enforcement of the existing legal provisions (Ayode and Tadele, 2010). 


\section{Cooperation of Stakeholders}

As most of the informants agreed that sex tourism business is a dynamic business practice which requires the link of different bodies. For instance, tour and travel agencies, receptionists, tourists, tourist guides, drivers, polices pensions and hotels should be involved for the business of sex tourism. It indicates that unless these all stakeholders are taking the issues and deal on it, eradicating such impacts of tourism on the local communities can not be possible.

One of the respondents from culture and tourism expert illustrated the following:

Sex tourism business has a long a hierarchy. It involves many channels. Each chain is connected properly to run the business. At least there should be a broker who can reach the tourists toward the local females and children. The workers of the hotel, the bell boys, the taxi and Bajaj drivers and others are working together to meet females and children with the sex tourists. It is conducted in the night. It is difficult to managed and control easily. Therefore, these all different sectors and stakeholders should give attentions for the problems to combat effectively.

Most respondents revealed that in tourism sector, there are many stakeholders who are working together. Most of the tourism stakeholders are linked to run the tourism activities. So to alleviate this negative implication of the tourism business, integrating and working all the tourism stakeholders is mandatory for keeping the dignity and indigenous culture of the society in particular and the country at large. The tour operators, travel agencies, hotels, airlines should develop codes of conducts and ethical policy against such exploitation, training their personnel in both the country of origin and travel destinations, providing information to travelers and to local key persons at the destinations, that child sex tourism is illegal and has awful consequences for children by means of catalogues, brochures, posters, in-flight films and other mechanisms (Valeriu, 2013).

\section{Conclusion}

The study was conducted to examine the sex tourism business practice at the tourist destination site in the case of Bahirdar City, Ethiopia. The study was focused on identifying the motivating factors, the effects of involving to the sex tourism business and it tried to assess some of the mechanisms which should be followed and implemented to prevent and combat the practices. As per the findings of the study told that poverty, peer pressure, modernization and migration, losing job opportunity, and globalization were the basic factors for most females and children to join the business. The effects of involving at the business were the transmitted disease, losing moral value and feeling loneness, bad image for the local destinations and for the country at large, as per the findings of the study, the mechanism to combat the practices were cooperation's of stakeholders, creating awareness, setting strict rules and regulations, establish polices against sex tourism business

\section{Recommendations}

$\checkmark \quad$ Families should be aware regarding the extent and the effects of the problem on females, children, local peoples and others.

$\checkmark$ The regional, zonal and woreda culture and tourism experts should give a great attention to the issues.

$\checkmark$ The females and children from the poor families should get proper training and follow up.

$\checkmark$ Thos who participate on contacting the sex tourist with the local females and children should get appropriate measurements.

$\checkmark \quad$ Tourist guides and receptions should inform when the problem is happen with their working area.

$\checkmark$ Series and hard laws, rules and regulations should be formulated to prevent the effects of the practices on female s and children.

$\checkmark$ The local communities should stand on behalf of the tourism industries to eradicate such business in the city.

\section{References}

Valeriu G, (2013) .Fighting “child sex tourism” Republic of Moldova, EPP/CD. Report of the Committee on Social Affairs, Health and Sustainable Development

Desta Ayode and Getnet Tadele (2010). An Assessment of Child Sex Tourism in Some Selected Tourist Attraction Sites in Ethiopia. ECPAT/FSCE in Collaboration with Ministry of Culture and Tourism

Hannum. (2002). "Children for Sale: Dateline goes undercover with a human rights group to expose sex trafficking in Cambodia.

Bunn D. (2011). Sex tourism. Papathanassis A. (eds).The Long Tail of Tourism. Gabler. https://link.springer.com/chapter/10.1007/978-3-8349-6231-7_3

Davidson and Taylor, (1995). Child Prostitution and Sex Tourism, GOA: Department of Sociology, University of Leicester, UK, September 1995.

Douglas Hodgson (1994). Sex Tourism and Child Prostitution in Asia: Legal Responses and Strategies, 19 MELB. 


\section{U. L. REV. 512, 515.}

Draft Declaration and Agenda for Action (1996). World Congress against Commercial Sexual Exploitation of Children at 2, Stockholm, Sweden (August 27-31).

ECPAT International (2008). Creating a United Front against the Sexual Exploitation of Children in Travel and Tourism. Hong Kong

ECPAT International, (2007). Patchareeboon Sakulpitakphon, confronting the commercial sexual exploitation of children in Africa. African Tourism Development and the Commercial Sexual Exploitation of Children: Programme Associate for Combating CST and Trafficking, ECPAT International 2007

Eva J. Klain,(1999). JD American Bar Association Center on Children and the Law for the National Center for Missing \& Exploited Children ,Prostitution of Children and Child-Sex Tourism: An Analysis of Domestic and International Responses

Frans de Man and Adama Bah (2013). 'Don't look away' be aware and report the sexual exploitation of children in travel and tourism: Assessment on sexual exploitation of children related to tourism and reporting mechanisms in Gambia, ECPAT the Netherlands.

FSCE (2008). The Situation of sexual abuse and commercial sexual exploitation of girl children in Addis Ababa.

Global Education Centre (2005). "Tourism Fact Sheet." Office to Monitor and Combat Trafficking in Persons. $<$ http://www.globaled.org.nz/schools/pdfs/factsheets/Tourism.pdf $>$

Janice Joseph (.......). Child victims of sex tourism: An International perspective

Kibicho (2009), Sex Tourism in Africa: Kenya's booming Industry.

Lim, L.L. (1998), the sex sector, International Labour Office, Geneva

Martha R. Gore (2009). Sex Tourism Trade Throughout the World, Travelers Taking Trips For Illicit Purposes, Jan 4, http://129.186.133.25/sapp/SlaveTrade2.pdf

O’Connell Davidson, J. (1998). Prostitution, power and freedom. Cambridge: Polity Press.

O'Connell Davidson, J. and Sanchez Taylor, J. (1999). Fantasy islands: exploring the demand for sex tourism. In: Kempadoo, K. ed. Sun, sex and gold: tourism and sex work in the Caribbean. Oxford: Rowman and Littlefield.

Phouthone Sisavath (2011). "Combating Child Sex Tourism in a new tourism destination, the United New Zealand degree of Master of Business

Saewyc EM, MacKay LJ, Anderson J, and Drozda C. (2008). It's not what you think: Sexually exploited youth in British Columbia. Vancouver: University of British Columbia School of Nursing

Sanders, T. (2008). Paying for pleasure: men who buy sex. Devon: Willan Publishing.

Tammy Quintanilla (1997). Globalization of sex trade, From the Summit to the Grassroots. http://www.socialwatch.org/sites/default/files/pdf/.

UNICEF (2005). Regional Assessment on Violence against Children in East Asia and the Pacific Region. UNICEF. Thailand. 2005

UNWTO, (2014). 15 Years of the UNWTO World Tourism Network on Child Protection: A Compilation of Good Practices. Spain 